\title{
MENGIDENTIFIKASI SIKAP TOLERAN SUNAN KUDUS MELALUI SITUS BUDAYA
}

\author{
Muhammad Rosyid \\ Institut Agama Islam Negeri Kudus, Jawa Tengah-Indonesia \\ Korespondensi: mrosyid72@yahoo.co.id
}

\begin{abstract}
Abstrak: Tulisan ini bertujuan mendedahkan fakta bahwa nilai toleransi perlu diuri-uri. Teknik perolehan data dengan observasi dan pendalaman literatur dengan analisis deskriptif kualitatif. Hasil riset, Kota Kudus Jawa Tengah terdapat situs khas di antaranya bangunan kuno disebut Langgar Bubrah. Bangunan itu terdapat lingga dan yoni sebagai karakter candi. Argumen ilmiah dengan pendekatan arkeologi menandaskan bahwa lestarinya Langgar Bubrah hingga kini sebagai bentuk toleransi Sunan Kudus yang tetap melestarikannya dilanjutkan oleh generasi muslim adanya lingga dan yoni hingga kini. Pemkab Kudus perlu optimal merawatnya sehingga diagendakan penyelamatan objek budaya yakni restorasi, revitalisasi, dan memfasilitasi sarana dan prasarana kebudayaan berupa fasilitas penunjang yakni ruang sanggar budaya. Anggota DPRD Kudus pun perlu mewujud politik anggaran dalam APBD yang berpihak pada cagar budaya dengan penyediaan pendanaan pemajuan kebudayaan didasarkan atas pertimbangan investasi.
\end{abstract}

Kata Kunci: Kota Kudus, Sunan Kudus, Sikap Toleran. 


\section{A. Pendahuluan}

Masa lalu dalam kajian sejarah merupakan data empiris dan menjadi pokok kajian. Masa lalu dapat berupa ragam peninggalan bersejarah di antaranya situs sejarah. Adanya situs sebagai penanda bahwa masa yang telah berlalu terdapat pelaku sejarah yang mewariskannya pada generasi kekinian. Di Jawa Tengah, terdapat Kota Kudus yang mendapat ragam julukan, yakni kota santri, kota budaya, dan kota bersejarah. Di Kota Kudus terdapat situs sebagai benda cagar budaya dan terdapat kekhasan sebagaimana peninggalan candi Hindu, warga Kudus memberi sebutan Langgar Bubrah/LB (selanjutnya ditulis LB). LB merupakan bangunan kuno yang diduga dimanfaatkan untuk tempat ibadah umat Hindu di Kudus masa lalu dengan bukti terdapat linggga dan yoni (LY). LY merupakan bentuk benda yang berada di bangunan kuno di Kudus hingga kini. Akan tetapi, hal yang disayangkan, Pemkab Kudus kurang memberi perhatian. Dampaknya, lahan bangunan cagar budaya tersebut lahannya kian menyusut dan benda peninggalannya banyak yang rusak karena minimnya perawatan.

LB kategori cagar budaya (CB) sehingga menjadi warisan budaya yang bersifat kebendaan. $\mathrm{CB}$ dapat berupa benda $\mathrm{CB}$, bangunan $\mathrm{CB}$, struktur $\mathrm{CB}$, situs CB, dan kawasan CB. CB harus dilestarikan karena CB memiliki kandungan makna penting untuk pengembangan ilmu pengetahuan khususnya arkeologi dan sejarah, kebudayaan, dan keagamaan. UU Nomor 11 Tahun 2010 tentang CB untuk menjadi pijakan hukum bagi publik dan penyelenggara negara bila merawat dan melestarikan peninggalan budaya bangsa. Awal mula diterbitkannya UU CB karena CB dipandang sebagai khazanah budaya bangsa dan perwujudan karya dan pemikiran anak bangsa. Konsekuensinya harus dilindungi, dikembangkan, dan dimanfaatkan untuk kemajuan budaya dan kesejahteraan rakyat. Pola pandangnya dengan melestarikan dengan pertimbangan aspek keilmuan, ideologi, dan ekonomi untuk kesejahteraan rakyat.

Kekhasan Kota Kudus memiliki peninggalan bersejarah berupa LB dan lestari sehingga muncul pertanyaan apakah lestarinya situs tersebut sebagai bukti Sunan Kudus dan generasinya hingga masa kini tetap melestarikan sebagai wujud toleran terhadap peninggalan Hindu?. logikanya, apabila tidak toleran, kemungkinan LB dimusnahkan. Tetapi, pelestariannya berhadapan dengan upaya 
pihak tertentu pasca-Sunan Kudus yang mengganti namanya menjadi Langgar Bubrah, bukan Sanggar atau Candi Bubrah. Langgar memiliki makna tempat ibadah bagi muslim atau tempat hunian. Dalam hal ini, bermakna tempat ibadah.

Para peneliti memiliki perhatian terhadap keberadaan Kota Kudus yang dapat dijadikan referensi penguat. Pertama, Himawan, bentuk Langgar Bubrah dibangun pada masa transisi dari Hindu-Buddha ke Islam sehingga nampak akulturasi pada mihrab (tempat berdoa) yang berwujud relung berada di bagian dinding sebelah luar. Relung ini dihiasi motif tetumbuhan sedangkan dindingnya (di sebelah tenggara) berupa relief seorang lelaki, rambutnya tertata rapi, posisinya berdiri serupa kepala sang Buddha. Di LB masih ada lumpang batu persegi panjang, panjangnya $95 \mathrm{~cm}$, lebarnya $45 \mathrm{~cm}$, tingginya $35 \mathrm{~cm}$, berbentuk sebagaimana batu pipisan (sarana pemujaan dan berfungsi penghalus biji-bijian). Difungsikan juga meramu jamu tradisional. Lumpang batu sebagai hasil karya budaya era Hindu-Buddha pra-Islam di Kudus (Himawan, 2012). Kedua, Roesmanto, Masjid al-Aqsha Kudus bentuknya serupa dengan bangunan Hindu, seperti candi di Jawa Timur antara lain Candi Kidal, Candi Jago, dan Candi Singasari. Keserupaan ini karena rupa dan bentuk Menara Kudus laksana bale yang memiliki konstruksi rangka kayu dan adanya kentongan yang menggantung di bagian atas, di bawah atap. Selain itu, memiliki bagian pejal yang tinggi sebagai penyangga bale (Roesmanto, 2013:10). Ketiga, Supatmo, Masjid Menara Kudus memiliki fenomena unik berupa gaya menaranya serupa dengan candi Hindu. Seni bangunan kompleks Masjid al-Aqsha Menara Kudus adalah berkesinambungan dengan gaya seni Hindu-Buddha (pra-Islam) dipadu gaya seni bangunan Islam dan seni hias (ornamen) pendukungnya. Ornamen makhluk bernyawa (figuratif) yang melatarbelakangi kepercayaan dan budaya menghiasi bangunan. Bentuk ini tidak lazim dalam tradisi seni hias dalam Islam (Supatmo, 2014). Keempat, Anisa, kawasan Kauman Menara Kudus merupakan kota lama atau cikal bakal Kota Kudus. Perekonomian warganya mempengaruhi tataruang kampung. Rumah tradisional Kudus berbentuk bangunan sisir wujud ruang khusus untuk aktivitas perekonomian. Rumah yang tidak terdapat bangunan sisir, aktifitas perekonomian di jogosatru (ruang digunakan untuk ruang publik) (Anisa, 2017). Karya para penulis tersebut mengkaji aspek tata ruang khas Kawasan Kauman Menara Kudus, 
hanya karya Himawan yang mengulas singkat tentang LB. Akan tetapi karya ini (penulis) mendalami aspek lain (sebagaimana tertuang dalam pertanyaan penelitian). Dengan demikian, naskah ini memiliki aspek kebaruan telaah bila dibanding para penulis tersebut sehingga perlu didalami.

Naskah ini untuk mengidentifikasi (1) apa saja fakta pembenar bahwa Langgar Bubrah sebagai benda cagar budaya?, (2) benarkah Sunan Kudus dan generasinya memiliki sikap toleran terhadap peninggalan umat Hindu di Kudus yang dibangun era pra-Islam di Kudus?, dan (3) apa upaya yang harus dilakukan dalam merawat situs yang bermakna toleran ? Tujuan ditulisnya naskah ini adalah mendapatkan fakta pembenar bahwa LB sebagai benda cagar budaya, benarkah Sunan Kudus dan generasinya bersikap toleran pada peninggalan Hindu di Kudus yang dibangun era pra-Islam di Kudus, dan mewacanakan pentingnya merawat cagar budaya yang memiliki makna toleransi Sunan Kudus atas keberadaan LB. Riset ini berharap memberi paparan tentang keberadaan situs dengan pendekatan ilmiah berdasarkan kajian arkeologi, tidak hanya berdasarkan cerita lisan yang non-ilmiah. Hal yang disayangkan, ragam hias di LB aus dimakan era yang belum optimalnya kepedulian Pemkab Kudus.

\section{B. Metode Penelitian}

Artikel ini hasil riset penulis tahun 2020 yang datanya diperoleh dengan wawancara, observasi, dan kajian pustaka. Wawancara dilakukan dengan perawat LB dan observasi di Dukuh Tepasan, Desa Demangan, Kecamatan Kota, Kabupaten Kudus, Jawa Tengah. Data dianalisis dengan pendekatan deskriptif kualitatif. Tahapan riset ini langkahnya (1) studi prariset pendahuluan dengan mengkaji literatur tentang LB, (2) survei pendahuluan untuk mengetahui kondisi riil LB, (3) survei lapangan dan pengumpulan data dengan observasi, wawancara, literatur dan dokumentasi, (4) menyusun sistematika penulisan dengan menentukan aspek bahasan obyek studi yang diuraikan dalam bab pembahasan, dan (5) diakhiri dengan simpulan dan daftar pustaka. 


\section{Pembahasan}

\section{Jejak Hindu di Indonesia}

Setiap agama ajarannya disosialisasikan pada khalayak umum oleh agamawannya, sebagaimana agama Hindu hingga ke Indonesia. Menurut Coedes, jejak peninggalan arkeologi dan sumber dari China menyatakan, peradaban Hindu pertama kali di Indonesia pada awal abad ke-5 M. Hal ini dibuktikan adanya prasasti era Raja Mulawarman di Kalimantan dan era Purnawarman di Jawa (Coedes, 2010:90). Prasasti Hindu di Kutai Kalimantan Timur membuktikan bahwa Raja Mulawarman mengundang hadirnya rohaniwan ajaran Siwa di Kutai. Dalam perkembangannya, agama Hindu ada di Jawa Tengah beraliran Hindu Siwa Trimurti, hadir juga pengaruh Buddha Mahayana. Di Jawa Tengah berkembang agama Buddha Mahayana dan Hindu Siwa antara abad ke- 8 s.d 10 M. Bukti sejarahnya berupa Prasasti Canggal berhuruf Pallawa berbahasa Sanskerta pada tahun 732 M ditemukan di Desa Canggal, Kedu, Jawa Tengah. Prasasti berisi cara memuja Dewa Siwa dalam Hindu. Di Desa Dinoyo, Malang, Jawa Timur juga ditemukan Prasasti Dinoyo tertulis tahun 760 M terkait agama Hindu (Darini, 2013:34). Pada abad ke-7 M keyakinan utama warga di Holing menurut Munoz adalah ajaran Siwa. Pada abad ke-8 meningkatnya penyebaran pertapaan Buddha atas kekuasaan Syailendra. Candi-candi Hindu diubah untuk ajaran Buddha seperti Candi Bima di dataran tinggi Dieng (Munoz,2009:182). Pewartaan pendeta Buddha I'tsing, tahun 664 datang Pendeta Hwi-ning dan Holing dibantu pendeta Jnanabhadra menerjemahkan beberapa Kitab Buddha Hinayana. Berita Tionghoa era Raja T'ang (618-906 M) disebutkan nama Kerajaan Kaling atau Holing di Jepara Jawa Tengah sejahtera penduduknya. Sejak tahun 674 M Kerajaan Holing dipimpin Ratu Simo/Sima (Dikbud Prov Jateng Museum Ronggowarsito, 2004:86). Prediksi lain, agama Hindu di Jawa sebelum Sanjaya sebagai raja di Medang Bhumi Mataram (717-760 M). Hindu pada posisi puncak kejayaan pasca Mpu Manuku Rakai Pikatan mendirikan Candi Siwagrha (rumah siwa) atau Candi Prambanan pada 12 November 856 M. Pada era Medang periode di Jawa Tengah sejak pemerintahan Mpu Manuku Rakai Pikatan hingga era Medang periode Jawa Timur, 
Kahuripan, Kadiri, Singhasari hingga Majapahit orang Jawa banyak pemeluk Hindu. Era kekuasaan raja terakhir Singasari (Kartanegara) berpaham Siwa Buddha, Kertanegara berperan sebagai sosok toleran yang melindungi umat Hindu aliran Siwa, pada waktu yang bersamaan, terjalin dengan pemeluk Buddha. Hanya saja, sejak Kerajaan Islam pertama di Jawa, Kesultanan Bintoro Demak, penduduk Jawa banyak yang berpindah menjadi muslim. Hindu yang tetap mempertahankannya berhijrah ke Bali. Setelah Majapahit (Girindrawardhana) tahun 11527 dijatuhkan oleh Sultan Trenggono, Kesultanan Demak, sejak itu Hindu mengalami era suram di Jawa (Achmad, 2017:27). Akan tetapi, hingga kini, penulis tidak memperoleh data sejak kapan Hindu ada dan berkembang di Kota Kudus.

\section{Kota Kudus Fase Awal}

Pada masa lalu, catatan arkeolog dan Kepala Penelitian Balai Arkeologi Yogyakarta Siswanto wilayah Kudus berupa laut. Kala itu ketika (Pulau) Gunung Muria terpisah dengan Pulau Jawa. Akibat dinamika alam yang ekstrem, Muria menyatu dengan Jawa, kemudian membentuk daratan Kota Kudus. Sempurnanya pendangkalan, abad ke-18 dalam catatan geologi tidak hanya membentangkan daratan baru Kudus juga Pati, Demak, dan sebagian Rembang serta Semarang sebagaimana kondisi kini. Fakta diperkuat foto koleksi Badan Arsip Nasional RI (ANRI) Jakarta bernomor register 573/38 KIT Jawa Tengah dan Yogyakarta (tidak menyebutkan tahun pemotretan). Keterangan foto/gambar (narasi) singkatnya ada vegetasi pantai di Residensi Kudus kala musim kemarau dengan pemandangan tumbuhan di pesisir (pandan), nelayan, udang, dan benda laut lainnya. Untuk memahami waktu pemotretan, dapat diuji di laboratorium forensik. Pada masa era glasial (saat air laut surut) Gunung Muria menyatu dengan Pulau Jawa. Tatkala es mencair akibat peningkatan suhu era interglasial, Gunung Muria terpisah dan terisolasi dengan Pulau Jawa. Fase perkembangan selanjutnya (abad ke-17 dan 18) (pulau) Gunung Muria bergabung lagi dengan Pulau Jawa (antara lain menjadi daratan Kudus). Hal ini dampak pelumpuran ekstrim sepanjang Pantai RembangSemarang Jawa Tengah. Daratan ini sebagian menjadi ruas jalan Deandeles dari Anyer (Banten) hingga Panarukan (Jawa Timur). Ada pula jalur kereta api, waduk, dan jaringan irigasi. Sebelum menyatu dengan Jawa, Gunung Muria merupakan 
gunung api aktif. Gunung Muria meletus dan mengubur peradaban purba yang kini berupa situs Patiayam yang semula Gunung Muria Purba di Kudus-Pati. Kini merupakan Gunung Muria yang baru. Ekskavasi di situs Patiayam ditemukan fosil binatang purba darat dan air, tengkorak manusia purba dan kapak perimbas terbuat dari batu. Oleh Siswanto disimpulkan, Patiayam masa lalu mengenal peradaban. Prediksi Siswanto, di selat antara Pulau Jawa dan Muria ada dua pulau yang terpendam. Terpisahnya laut dan menyatu (Pulau) Gunung Muria dan Jawa tidak terlepas Kudus masa kini. Kudus Kuno menurut Siswanto adalah kawasan Kudus Kulon. Pada abad ke-15 Sunan Kudus membangun di Kawasan Kauman Menara. Adapun Kudus Wetan (sebelah timur Sungai Gelis) merupakan wilayah baru yang dulu berupa laut yang diarsitekturi Belanda (Suara Muria, Suara Merdeka, 18 November 2014, hlm.23).

Catatan VOC, Kudus hingga abad ke-17 berada di daratan pulau Jawa, orang dapat berlayar keliling Gunung Muria dengan perahu kecil (Van Bemmelen). Dalam Map of Java yang diterbitkan Geraard van Kuelen edisi pertama 1728 M, Prof. Adriana Reland menyebut Gunung Muria de berg van Japara. Nama Kudus dari prasasti di mihrab Masjid Menara Kudus tertulis: “Dengan nama Allah yang Maha Pengasih dan Maha Penyayang. Telah mendirikan masjid al-Aqsha ini di negeri Kudus, khalifah pada zaman ulama dari keturunan Muhammad untuk membeli kemuliaan surga yang kekal, untuk mendekat Allah di negeri Kudus. Membina masjid al-Manar yang dinamakan al-Aqsha khalifatullah di bumi, yang agung dan mujtahid yang arief, kamil fadhil al-maksud dengan pemeliharaan al-Qodli Ja'far Shodiq tahun 956 hijrah Nabi SAW".

\section{Fakta Pembenar Langgar Bubrah sebagai Peninggalan Hindu Kuno}

Kata 'kauman' dikiratabahasakan dari kata 'kampung orang beriman'. Warganya diidentikkan taat beragama. Fakta penguatnya, ada masjid, lembaga keislaman, dan terlestarikannya budaya Islam. Di perkotaan, kauman diidentikkan dengan warganya berprofesi sebagai wirausahawan yang memanfaatkan tataruang untuk bisnis sebagai sumber ekonominya. Akan tetapi, berbeda dengan Kauman Yogyakarta, menurut Darban, terkait dengan Keraton Yogyakarta yang menempatkan abdi dalem pamethakan berkarya di bidang keagamaan 
(kemasjidan) dengan lokasi khusus. Keluarga abdi dalem membentuk komunitas yang lokasinya disebut Kampung Kauman (Darban, 2010:2). Kauman Kudus pun semula kawasan yang identik dengan jiwa wirausaha bagi warganya. Akan tetapi, kini Kauman Kudus mengalami perubahan karena rumah adat sebagai bangunan bersejarah beralih fungsi karena dijual, dibagi waris yang masing-masing ingin bertahan di wilayah kauman sehingga berdampak terhadap tata letak kampung yang padat.

Upaya mengidentifikasi peninggalan Hindu di Kudus dengan memahami karakter situs yang dimiliki oleh peninggalan Hindu. Karakter dapat berupa (1) lingga, (2) yoni, (3) pintu dalam dan luar bangunan pura (kori), (4) balai tajug (bangunan di area bagian terluar pura/setelah kori berfungsi untuk rapat keagamaan, tempat membuat sesajen, dan tempat sesajen). Keempat ciri tersebut yang ada di LB hanyalah lingga dan yoni. Langgar Bubrah jaraknya $200 \mathrm{~m}$ dari kawasan Kauman Menara Kudus, di Dukuh Tepasan, Desa Demangan, Kecamatan Kota. Situs budaya bersejarah (LB) memiliki kekhasan yakni bangunan yang ada sebagaimana cadi yakni adanya lingga dan yoni.

LB merupakan bangunan kuno yang kondisinya kini sudah lapuk dindingnya, bahkan posisinya miring. Tapi belum ada upaya merawat oleh Pemkab Kudus. Langgar Bubar dari kata langgar (bagi orang Jawa bermakna musala/tempat salat) dan bubrah dalam bahasa Jawa bermakna bangunan yang belum selesai pengerjaan sehingga tidak sempurna (belum jadi). Bangunan karya umat Hindu terdapat lingga dan yoni sebagai simbol atau media berdoa hamba dengan Sang Hyang Widi Wase (Tuhan). Riset Hastutiningsih, Candi Sukuh sebagai tempat yang disucikan/disakralkan umat Hindu terdapat simbol manifestasi Dewa yang diagungkan berupa lingga dan yoni. Keberadaannya sebagai lambang Dewa Syiwa, makna lainnya sebagai perlambang kesuburan. Lingga tersebut dilingkari yoni berantai bunga, maknanya sebagai penanda pentingnya ikatan perkawinan. Selain itu, bermakna bahwa hubungan suami-isteri (persetubuhan) sesuatu yang disakralkan/disucikan. Kedua simbol (yoni dan lingga) juga berfungsi sebagai media pengobatan (Hastutiningsih, 2008:48). Karya Hastuti sebagai penegas bahwa lingga dan yoni menyimbolkan tempat suci bagi umat Hindu. 
LB berada di pinggir jalan perkampungan yang rumah warganya lazim di pagar tembok tinggi. LB berada di atas tanah seluas 8,74 $\mathrm{m} \times 8,40 \mathrm{~m}$ persegi, panjang 6,30 m, lebar $6 \mathrm{~m}$, tinggi 2,75 m, luas bangunan 37,80 m. LB diprediksi dibangun tahun 932 H/1546 M (tahun ini berdasarkan cerita lisan, bukan hasil riset arkeologi) oleh Pangeran Pontjowati, yakni Senopati (pasukan perang) Sunan Kudus. Dikisahkan, langgar direncanakan dibuat dalam waktu semalam, akan tetapi karena ketahuan orang di sekeliling lokasi maka pembangunan diurungkan. Mihrab-nya (tempat berdoa) terdapat relung di dinding sebelah luar dengan hiasan bermotif tumbuhan, dinding sebelah tenggara terdapat relif lelaki yang rambutnya tertata seperti kepala Buddha dalam posisi berdiri. Ada lumpang batu persegi panjang panjangnya $95 \mathrm{~cm}$, lebar $45 \mathrm{~cm}$, tinggi $35 \mathrm{~cm}$, berbentuk seperti batu pipisan (yang diduga digunakan penghalus biji-bijian, meramu jamu tradisional, atau sarana pemujaan Dewa). Ada pula batu bundar berlubang pada bagian tengahnya (berbentuk lumpang) dengan istilah lain yoni sebagai lambang kewanitaan atau lambang bumi. Kata yoni dari bahasa Sanskerta berarti bagian/tempat (simbol kandungan) untuk melahirkan anak. Kaitannya dengan batu candi, yoni berarti (pasangan lingga) sebagai simbol alat kelamin wanita (tara). Lingga dalam mitologi Hindu diibaratkan alat kelamin lelaki (phallus), lambang Siwa sebagai dewa semesta. Dalam terminologi Hindu lingga dan yoni sebagai pembangkit kundalini, maksudnya prosesi naik pada proses dan tahap yang lebih tinggi. Fungsi yoni sebagai pelengkap lingga yang melambangkan kesuburan. LB dijadikan sebagai BCB tahun 1991, di LB ada batu lingga panjangnya $125 \mathrm{~cm}$, luas lingkaran $155 \mathrm{~cm}$, tinggi $125 \mathrm{~cm}$, bergaris tengah $45 \mathrm{~cm}$ sebagai lambang Dewa Siwa, simbol kesatuan abadi atau Dewa yang tidak berbentuk. Dalam kajian ini, lingga lebih mendekati bila diberi makna titik tugu pemujaan dewa, sedangkan yoni didefinisikan sebagai organ kandungan yang melahirkan Brahmana dan dewa lainnya. Berarti pula perwujudan arca, manifestasi dewa, bentuk ikon Siva. Di kompleks LB terdapat yoni panjangnya 200 $\mathrm{cm}$, lebar $35 \mathrm{~cm}$, tinggi $15 \mathrm{~cm}$, luas tanah $74 \mathrm{~m}$ persegi, dan luas bangunan $10 \mathrm{~m}$. Diprediksi pada abad ke-14 M. Pada bagian pilar bawah terdapat relief patung Dewa Siwa berdiri memegang senjata trisula. Diperkirakan, sebelum didirikan LB, telah didirikan candi Hindu (Supani, 2009:11). Prediksi penulis pun karena kisah 
tersebut dalam hal pembuat dan tahun pembuatan tidak berdasarkan kajian arkeologi tapi cerita rakya, dapat diprediksi semula peninggalan Hindu yang tak terawat karena minimnya umat Hindu pasca berkembangnya Islam di Kudus. Dalihnya, yoni dan lingga dalam Islam tidak tertradisi. Dengan demikian, yang urgen dilakukan adalah riset berbasis arkeologi. Riset arkeologi menurut Mundardjito dengan tiga tahapan yakni pengumpulan data, analisis dan rekonstruksi data, dan pelaporan atau publikasi hasil kedua tahapan tersebut. Dalam mengumpulkan data, tekniknya dengan penjagaan (untuk mengetahui keutuhan data arkeologi, survei permukaan tanah, bawah tanah, potret udara, eskavasi lubang uji (test-pit) dan wawancara; eskavasi dengan teknik spit, lot, lapisan tanah (layer) atau teknik lain yakni sedot dan lapis demi lapis (untuk eskavasi obyek di bawah air). Teknik pengumpulan datanya berdasarkan sifat, kontur, dan kondisi lapangan. Hasil pengumpulan data (1) artefak (benda dari alam yang dimodifikasi oleh peneliti (sebagian atau seluruhnya), (2) ekofak (benda dari alam yag diduga oleh peneliti telah dimanfaatan oleh manusia), (3) fitur (artefak yang tak dapat diangkat dari tempat semula). Pada tahap survei dan eskavasi juga dilakukan perekaman data berupa catatan, gambar, peta, formulir, foto, dan vidio pada artefak, ekofak, dan fitur dan lingkungan sekitar obyek riset (situs). Setelah itu, mengolah data dengan (1) mengklasifikasi awal bahwa artefak dan ekofak terkumpul dan dibersihkan, dicatat proses penemuannya, difoto/digambar, diklasifikasi awal berdasar kategori artefak, ekofak, dan hasil perekaman data. Dalam merekam data, langkahnya, penomoran dan penginventarisan berdasarkan kategori, pengkatalogisasian dan pemilahan berdasarkan kategori, dan penyimpanan berdasarkan kategori. Setelah itu, analisis dan rekonstruksi, dan pelaporan (Mundardjito, 1999:21). Dapat pula melakukan penelirian arkeologi melalui empat langkah surveys, excavations, archival research, and oral history interviews. Survei permukaan dilakukan agar mendapat artefak, keadaan geofisika dan topografinya. Eskavasi dilakukan untuk membuktikan dan menemukan jejak masa laalu dari artefak yang terkubur dalam tanah. Arsip masa lalu sebagai sumber yang tercatat atau tersimpan sebagai tulisan sejarah dan peta dan foto kuno untuk digunakan menganalisa dan menginterprtasi. Wawancara sejarah lisan untuk mendapatkan data pribadi atau kelompok sosial 
dalam ingatan saksi atau pelaku sejarah atas komunitas tertentu (Cassela, 2005:15). Ada empat tahap penggolongan data dan analisa mencari makna simbolik di balik wujud fisik yakni (1) mengidentifikasi persamaan dan perbedaan fisik bangunan, (2) merinci pembeda yang ada, (3) memberi konteks sosial tertentu pada data yang ada, dan (4) menginterpretasikan agar diperoleh kejelasan makna simboliknya (Anisa, 2017:4).

Dengan upaya tersebut diharapkan diperoleh jawaban atas pertanyaan apa fakta pembenar bahwa Langgar Bubrah sebagai situs Hindu dan apa upaya Pemkab Kudus merawatnya.

\section{Sikap Toleran Sunan Kudus atas Peninggalan Umat Hindu di Kudus Pra-Islam}

Kata toleran atau toleransi secara sederhana adalah upaya seseorang atau sekelompok orang yang sikapnya tidak memusuhi pihak lain yang seagama atau berbeda agama atau seagama tapi berbeda aliran. Konteks toleran Sunan Kudus yang dikaji dalam naskah ini yakni tidak melakukan pemusnahan situs budaya masa Hindu di Kudus pra-Islam. Hanya saja, dilihat dari aspek penamaan situs terjadi perubahan yang semula (diduga) bernama sanggar menjadi langgar. Kata sanggar identik dengan candi. Dugaan perubahan tersebut diperkuat adanya kekhasan sebuah bangunan yang memiliki ornamen atau benda yang ada di candi yakni lingga dan yoni. Kedua benda tersebut hingga kini masih utuh dan berada di area cagar budaya LB. Penamaan tersebut, hemat penulis oleh generasi pascaSunan Kudus dengan mempertimbangkan hal tertentu yang perlu pendalaman pada topik lain.

Hal yang memprihatikan, kini kodisi Langgar Bubrah areanya kian terdesak oleh pelebaran halaman oleh penghuni rumah di sekitarnya. Fakta ini dapat dikroscek dengan foto Langgar Bubrah era kolonial Belanda yang tidak sesempit areanya sebagaimana kini. Agar 'tuduhan' ini tak menjadi hoax, Pemkab Kudus harus bekerja sama dengan Badan Pertanahan Nasional Kabupaten Kudus untuk melakukan ceking sertifikat lahan penghuni. Hal ini sebagai upaya untuk memperoleh kepastian status lebar dan luasnya lahan Langgar Bubrah. Hal pokok yang harus dilakukan adalah melakukan upaya pendekatan yang arif dan santun untuk mengurangi ketersinggungan pemilik lahan. Bila hal ini terlaksana, langkah 
selanjutnya adalah Pemda memerlukan kepedulian merawat dengan dana yang ideal dari APBD Kudus. Merawatnya berdasarkan kalkulasi Tim Ahli Cagar Budaya (TACB) yang telah dibentuk oleh Bupati Kudus tahun 2019 dan bekerja sama dengan Tim Balai Pelestarian Cagar Budaya Provinsi (BPCB) Jawa Tengah. Kondisi bangunan Langgar Bubrah yang makin tua hingga kondisi bangunannya miring, hiasan dan ornamennya kian pudar akibat termakan cuaca perlu perbaikan. Merawatnya harus merujuk pada UU Nomor 11 Tahun 2010 tentang Cagar Budaya (CB) dan UU Nomor 5 Tahun 2017 tentang Pemajuan Kebudayaan. Bentuk toleran Sunan Kudus konteks bangunan Langgar Bubrah adalah masih dilestarikannya lingga dan yoni di LB hingga kini.

\section{Upaya Penyelamatan Cagar Budaya Bermakna Toleran}

Poin pokok yang menjadi bahan pertimbangan diterbitkannya UU Nomor 5 Tahun 2017 tentang Pemajuan Kebudayaan perlu dijadikan dasar Pemkab Kudus melestarikan cagar budaya berupa bangunan kuno di Kudus antara lain Langgar Bubrah. Pertimbangan utama UU (1) pemajuan kebudayaan untuk investasi nasional, (2) identitas kebudayaan nasional, (3) butuh dilindungi, dikembangkan, dimanfaatkan, dan dibina untuk terwujudnya bangsa yang berdaulat.

Atas dasar pijakan tersebut, Pemkab Kudus harus menyelamatkan objek budaya (amanat Pasal 26 (1) UU Nomor 5 Tahun 2017) dengan ragam upaya. Pertama, restorasi yakni mengembalikan/memulihkan obyek pemajuan kebudayaan ke keadaan semula (Pasal 26 ayat 3 poin c). Kondisi Langgar Bubrah kini sangat memprihatinkan, mengapa? tidak mendapat perhatian perawatan secara periodik dan rutin oleh Pemkab Kudus c.q Dinas Kebudayaan dan Pariwisata. Fakta pembenarnya, tidak ada alokasi anggaran perawatan meski telah dibentuk tim ahli cagar budaya (TACB). Kondisi atapnya miring, pernik hiasan dinding memudar karena cuaca. Padahal, sebagian warga di Kudus ada yang masih memanfaatkannya untuk media berdoa dalam mengawali bila warga memiliki hajat (menantu, mengkhitankan, mendirikan rumah, dsb.). Warga di sekitar LBpun tidak nampak peduli. Kedua, revitalisasi yakni menghidupkan kembali obyek pemajuan kebudayaan yang nyaris musnah. Anggota DPRD Kudus harus pula dilibatkan aspek politik penganggaran APBD Kudus agar ada keberpihakan 
terhadap cagar budaya. Wujud riilnya menyediakan dana perawatan cagar budaya dengan dasark dan pertimbangan investasi (Pasal 47 UU Nomor 5 Tahun 2017).

\section{Kesimpulan}

Lestarinya situs cagar budaya Hindu Kuno di Kota Kudus Jawa Tengah adanya yoni dan lingga di LB sebagai fakta bahwa Sunan Kudus hadir di Kudus telah ada situs tersebut dan tidak memusnahkannya sebagai wujud toleran. Pesan toleran perlu diikuti jejaknya oleh generasi di Kudus masa kini. Pemerintah Kabupaten Kudus harus pula merawatnya karena kondisi fisik LB kini tidak lagi utuh akibat cuaca. Merawat benda cagar budaya yang memiliki nilai sejarah harus dilakukan oleh ahli cagar budaya. Perawatan BCB memerlukan kiprah politisi dalam hal anggaran yakni memihak benda bersejarah agar dapat dijadikan alternatif utama destinasi wisata sejarah yang memiliki pesan toleransi. Lingga dan yoni sebagai cirri peninggalan Hindu, di Kudus satu-satunya yang masih utuh hanyalah di LB sehingga merawatnya oleh warga setempat, masyarakat Kudus, DPRD Kudus dan Pemda Kudus sebagai sebuah keniscayaan. 


\section{Daftar Pustaka}

Achmad, Sri Wintala. Asal-Usul Sejarah Orang Jawa. Araska: Yogyakarta. 2017.

Anisa. Keterkaitan Aktivitas Ekonomi dengan Tata Ruang Rumah Tradisional Kudus di Kota Lama Kudus. Makalah Seminar Nasional Sains dan Teknologi 2017 Fakultas Teknik Universitas Muhammadiyah Jakarta, 1-2 November 2017.

Cassela, Eleanor Conlin. Social Workers: New Directions in Industrial Archeology. In James Symonds (Ed), Industrial Archeology: Future Directions (pp.3-32). Washington DC: Springer Science and Business Media Inc, 2005.

Coedes, George. Asia Tenggara Masa Hindu Buddha. KPG Ecole Francoise d' Extreme-Orient Forum Jakarta Paris Puslitbang Arkenas: Jakarta. 2010.

Darban, Ahmad Adaby. Sejarah Kauman Menguak Identitas Kampung Muhammadiyah.Suara Muhammadiyah: Yogyakarta. 2010.

Darini, Ririn. Sejarah Kebudayaan Indonesia Masa Hindu Buddha. Ombak: Yogyakarta. 2013.

Dinas Pendidikan Pemprov Jateng, Museum Ronggowarsito. Artefak Batu Masa Prasejarah Hindu-Buddha (Koleksi Museum Ronggowarsito). Semarang.2004.

Hastutiningsih, Tri. Simbol-Simbol Agama Hindu di Candi Sukuh (Studi Simbol Agama Hindu di Dusun Sukuh, Kecamatan Ngargoyoso, Kabupaten Karanganyar, Jateng. Skripsi UIN Sunan Kalijaga Yogyakarta. 2008.

Himawan, Ulya. Langgar Bubrah, sebuah Akulturasi Hindu-Islam. Gangsiput.com, 8 Juli 2012.

Mundardjito. Metode Penelitian Arkeologi. Puslit Arkenas, Depdiknas: Jakarta. 1999

Munoz, Paul Michel. Kerajaan Awal Kepulauan Indonesia dan Semenanjung Malaysia Perkembangan Sejarah dan Budaya Asia Tenggara (Zaman Prasejarah hingga Abad XVI). Mitra Abadi: Yogyakarta. 2009.

Nuralia, Lia. Struktur Sosial pada Rumah Pejabat Tinggi Perkebunan Zaman Hindia Belanda di Jawa bagian Barat. Jurnal Kapata Arkeologi. Vol. 13, Nomor 1, Juli 2017.

Roesmanto, Totok. Rupa Bentuk Menara Masjid Kudus, Bale Kulkul, dan Candi. Jurnal Arsitektur Universitas Bandar Lampung. 2013.10-17.

Supani, Sancaka Dwi, dkk. Benda Cagar Budaya Peninggalan Sejarah dan Purbakala Kabupaten Kudus. Dinas Kebudayaan dan Pariwisata Kudus.2009.

Supatmo. Keunikan Ornamen Bermotif Figuratif pada Kompleks Bangunan Masjid Menara Kudus. Jurnal Fakultas Bahasa dan Seni Unnes, Vol.VIII, No.1 Januari 2014. 